\title{
Corpus Luteum Development
}

National Cancer Institute

\section{Source}

National Cancer Institute. Corpus Luteum Development. NCI Thesaurus. Code C92923.

The process by which the ovarian follicle becomes the corpus luteum. It occurs after ovulation. 